\title{
МЕСТО НЕПОИМЕНОВАННЫХ В ГЛ. 23 ГК РФ СРЕДСТВ ВОЗДЕЙСТВИЯ НА ДОЛЖНИКА В СИСТЕМЕ СПОСОБОВ ОБЕСПЕЧЕНИЯ ИСПОЛНЕНИЯ ОБЯЗАТЕЛЬСТВ
}

Аннотация: Предметом исследования данной статьи является рассмотрение и анализ непоименованных средств воздействия на должника в системе способов обеспечения исполнения обязательств, которые, в свою очередь, на сегодняиний день мало исследованы в науке гражданского права. Так же в статье, подробно раскрыты такие понятия как непоименованный договор и все возможные непоименованные способы и средства воздействия на должника. Кроме того, автор раскрывает и описывает не маловажную роль института обеспечения исполнения обязательств. Методами исследования в статье является применение примеров из практики в данной области и внедрение собственных разработок. В рамках данной статьи автор, использует и применяет конкретные примерь из практики, а так же приводит собственную классификацию непоименованных способов обеспечении исполнения обязательств, и раскрывает особенности законодательного нормирования каждой из выявленных групп. Кроме того, автор приходит к выводу, что на сегодняшний день в гражданском законодательстве нет четко сформулированного механизма правового регулирования всех непоименованных средств обеспечения обязательств. Ключевые слова: Обязательства, обеспечение обязательств, непоименованнье способы обеспечения, неустойка, задаток, заранее определенные убытки, поручительство, гражданское законодательство, сочиально-юридическая значимость, свобода договора.

Abstract: The subject of this research is the review and analysis of the non-defined means of influencing a debtor within the system of ensuring fulfillment of obligations, which are currently insufficiently researched within the science of civil law. The article also clarifies such notions as non-defined contract and all possible non-defined means and ways of affecting the debtor. The author also unravels and describes the important role of the institution of ensuring fulfillment of obligations. In this article the author uses and applies specific examples from precedent, as well as offers original classification of non-defined methods of ensuring fulfillment of obligations and illuminates the aspects of legislative regulation of each of the presented groups. The author comes to the conclusion that there is currently no clearly formulated mechanism for legal regulation of all non-defined means of ensuring fulfillment of obligation in civil legislation.

Keywords: Obligations, Fulfillment of obligations, Non-defined means, Penalties, Down payment, Predetermined losses, Co-signing, Civil legislation, Socio-legal significance, Freedom of contract.

B се нормы гражданского законодательства, содержащиеся в Гражданском кодексе РФ (далее - ГК РФ), и в иных законодательных актах, базируются на фундаментальных принципах гражданского права, которые создают вектор направления соответствующего правового регулирования. Изначально все принципы гражданского права находятся в юридически равном положении. Однако среди этих принципов выделяются такие, которые в силу своей особой социально-юридической значимости занимают положение первых среди равных (primus inter pares). Одним из таких фундаментальных принципов является принцип свободы договора, который, в свою очередь, является продолжением гражданско-правового принципа - принципа автономии воли сторон.

Принцип свободы договора является ведущим цивилистическим принципом. Содержательная сторона принципа свободы договора, имеет несколько разно- плановых правовых граней, а сами эти грани являются конкретными и конечными «свободами», которые входят в содержание данного принципа. Принцип свободы договора (его составляющие элементы) подразумевает свободу в решении вопроса о заключении или не заключении договора, выборе контрагента по договору, определении содержательной составляющей договора и многое другое. Одной из таких граней как раз и является возможность участников гражданского оборота заключать так называемые непоименованные договоры, т.е. такие договоры, которые напрямую не регламентируются действующим гражданским законодательством, и чье юридическое содержание, выражающееся в конкретных правах и обязанностях его участников, изначально будет находиться в сфере правового вакуума. Другими словами, непоименованный договор это такое договорно-правовое явление, которого нет в гражданском законодательстве, но в свою очередь, его 
DOI: $10.7256 / 1811-9018.2015 .6 .15449$

При цитировании этой статьи сноска на dоі обязательна

\section{Право и политика $6(186) \cdot 2015$}

появление имеет место быть по инициативе участников гражданского оборота и только с наличием неких условий, получит соответствующее признание в юриспруденции и правовую защиту в целом.

Непоименованным договорам в ГК РФ зеленый свет дают две его нормы. Первая норма - норма общего содержания, посвященная основаниям (источникам) возникновения гражданских прав и обязанностей. Подп. 1 п. 1 ст. 8 ГК РФ прямо указывает, что гражданские права и обязанности возникают из договоров и иных сделок, предусмотренных законодательством, а также из договоров и иных сделок, хотя и не предусмотренных законодательством, но не противоречащих ему.

Вторая, уже частная норма, содержится в п. 2 ст. 421 ГК РФ (статья посвящена принципу свободы договора), где предусматривается, что стороны имеют вероятность заключать не только предусмотренный законом договор, но и не предусмотренный законом или другими правовыми актами.

Если говорить в более общем плане, то возможность заключения и правомерного существования непоименованных договоров является правилом мировой цивилистики в целом, а сама эта конструкция является, распространенной повсеместно.

Договоры, не урегулированные действующим законодательством, в теории называют непоименованными, безымянными[1], инноминативными[2], нетипичными[3c.4-19], аномальными[2 с.8], неквалифицированными[6 с.17], договорами необычного содержания[3 с.106].

Понятие «непоименованный договор», являющееся наиболее распространенным в юридической литератуpe, на протяжении истории своего развития наполнялось различным содержанием.

В римском праве группа договоров, не относящихся ни к консенсуальным, ни к реальным, не имела самостоятельного обозначения и лишь противопоставлялась тем договорам, которые nomen suum babent (имели свое наименование). Впоследствии в науке римского права такие договоры получили название contractus innominati (непоименованные договоры). Обязательство из таких договоров возникало лишь после исполнения одной из сторон обещанного представления (иного, чем передача вещи), что и послужило объединяющим признаком группы непоименованных договоров.

Анализируя существовавшее в дореволюционном гражданском праве деление договоров на «самостоятельные» (урегулированные законодательством) и «несамостоятельные», известный российский юристцивилист Д. И. Мейер, подверг сомнению уместность используемых терминов, так как к «несамостоятель- ным» договорам целесообразно относить такие, которые «не существуют сами по себе, а составляют лишь дополнение к другим договорам». Более уместным, по его мнению, являлось использование терминов «именные» и «безымянные» договоры, несмотря на то, что в римском праве деление договоров на contractus nominati и contractus innominati имело совершенно другое значение [5 c.158].

В настоящее время термин «непоименованные договоры» используется для обозначения договоров, не урегулированных действующим законодательством.

Различные подходы к содержанию понятия «непоименованный договор» обусловлены отсутствием законодательного закрепления рассматриваемого термина. В отличие от смешанного договора, непоименованный договор остается за рамками правового регулирования. Проблемы в правоприменении и противоречия в судебной практике, обусловленные отсутствием законодательного регулирования непоименованных договоров, отмечались еще Д. И. Мейером[5 с.500], и К. П. Победоносцевым[7 с.60-61].

В русском гражданском праве, возможность заключения договоров, прямо не указанных в Своде законов Российской империи или иных законодательных актах, не ставилось под сомнение. Статьи 569 и 570 Свода законов Российской империи, прямо не упоминали о непоименованных договорах, однако ясно указывали, что «любой договор», предписывает обязанность его исполнять и дает право на иск, если они правильно составлены. Судебная практика также допускала существование непоименованных договоров.

Свободу выбора сторонами типа договора, а также вероятность заключать непоименованные договоры с распространением на них общих положений об обязательствах прямо закрепляла ст. 1570 проекта Гражданского уложения [8 c.177].

В первом Гражданском Кодексе РСФСР 1922 г. о свободе договора не упоминалось, ввиду того, что принцип дозволенности заключать любой договор[9 с.91], в нем не был закреплен.

Положительно решился вопрос о правовой защите многих неизвестных ГК РСФСР и другим правовым актам видов договоров, в Гражданском Кодексе РСФСР 1964 г., где законодательно было закреплено, что права и обязанности граждан возникают из предусмотренных законом сделок, а также из сделок не предусмотренных, но не противоречащих закону (ст. 4).

После 1964 г., в условиях плановой экономики, свобода заключения непоименованных договоров, реализовывалась только во взаимоотношениях граждан. 
В настоящее время, правовая основа для заключения непоименованных договоров, и их судебная защита изложена в п. 2 ст. 421 ГК РФ, где указано, что стороны имеют право заключать договор предусмотренный, и не предусмотренный законом, а также другими правовыми актами.

Договоры, в отношении которых в законе нет обобщающего регулирования, являются непоименованными. Так, например, п. 1 ст. 247 ГК РФ (имущество, которое находится в долевой собственности, исполняется (владение и пользование) по соглашению всех его участников) или ст. 152.1 ГК РФ (использование фотографии (изображения) гражданина, возможно только с его согласия).

При таком подходе к соглашениям, договор, в рамках которого дано такое согласие, будет являться непоименованным, так как кроме этого упоминания в российском законе, ни в актах судебного правотворчества не содержится специального регулирования таких соглашений.

Если же выносится хоть единичный акт судебного правотворчества в отношении такого договора, то такой договор утрачивает основания считаться непоименованным.

Таким образом, такие договоры, продолжая именоваться непоименованными, могут постепенно обрастать специальными нормами судебного правотворчества.

На основании анализа содержания условий договора и направленности воли сторон, судом осуществляется квалификация договора. Однако это характеризует процесс квалификации договора с одной лишь стороны. Для признания договора непоименованным, следует заранее исключить возможность признания его поименованным.

Определяя направленность воли сторон и суть порождаемых ею прав и обязанностей, суд соотносит содержание договора с известными в праве договорными моделями, чтобы показать ту, под которую можно подводить заключенный договор. Если же заключенный договор не соотносится ни с одной из поименованных моделей, он возводится в разряд непоименованных, что означает применимость к договору исключительно общих положений обязательственного и договорного права.

Система структурирования нормативного регулирования договорных правоотношений полагает выделение общей части обязательственного права и особого регулирования конкретных поименованных договоров. Наличие особого регулирования отдельных договоров полагает законодательную фиксацию квалифицирующих признаков, которые относят контракт, заключенный сторонами, к соответствующей поименованной договорной категории. При соответствии заключенного соглашения сторон всем квалифицирующим признакам поименованного договора его подводят под установ- ленный поименованный договорный тип. При несоответствии квалифицирующих признаков его подводят под непоименованный статус договора.

В настоящее время, на практике сформировались стабильные конструкции непоименованных договоров (рамочный договор, опционный договор, договор о передаче прав и обязанностей по ранее заключенному договору и т.д.). Смешанным договором в силу п. 3 статьи 421 ГК РФ признается такой договор, который включает элементы различных договоров, предусмотренных законом или иными правовыми актами РФ.

Таким образом, из приведенного законоположения, следует что, хотя бы один из элементов смешанного договора должен быть предусмотрен в законе. Включение в договор элементов только непоименованных договоров свидетельствует о том, что перед нами именно непоименованный договор, а не смешанный. Его правовое регулирование осуществляется, исходя из п. 2 статьи 421 ГК РФ: к нему подлежат применению общие правила ГК РФ об обязательствах и договорах с учетом соглашения самих сторон такого непоименованного договора.

Особое место в системе мер, направленных на реализацию цели обязательства, занимает институт обеспечения исполнения обязательств. Использование обеспечения объясняется, основным интересом кредитора в уверенности исполнения обязательств и обеспечения возмещения убытков, которые возникают при случае неисполнения обязательств.

Согласно п. 1 ст. 329 ГК РФ, способы обеспечивающие исполнение всех обязательств, устанавливаются договором или законом. Вместе со способами, указанными в ГК РФ, сторонам дана возможность применять другие правовые конструкции.

Учитывая, что общепринятые и традиционные способы обеспечения достигли своего предела, а так же возможной эффективности, но исчерпали потенциал своего развития, как устоявшиеся конструкции. Следовательно, развитию института обеспечения в будущем, нужно двигаться в направлении конструирования абсолютно новых, способов обеспечения, которые ранее в законе еще не упоминались.

Для того, что бы выделить непоименованные способы обеспечения из всей массы правовых инструментов, которые участники оборота применяют, в свою очередь от авторов поступают предложения по применению некого оценочного критерия, который можно назвать как «самостоятельная способность влечь имущественные последствия». Представляемые как «имущественную гарантию кредитора» которая, обеспечивается путем «резервирования источника будущих выплат»[18 с.77]. 


\section{Право и политика $6(186) \cdot 2015$}

Данный признак сформулирован таким образом, что возвращает именно к целевой трактовке способов обеспечения. Кроме того, данный признак имеет для всех способов обеспечения обязательств, общее и универсальное значение, но в практике, наиболее удобен для отбора и поиска «инициативных». В процессе развития непоименованных способов обеспечения обязательств могут быть внесены существенные корректировки. В случае если участникам оборота будут предоставлены четкие ориентиры в отношении общих признаков способов обеспечения обязательства. Если внести в гражданское законодательство отдельное понятие обеспечения обязательства, либо дополнить ст. 329 ГК РФ и внести в нее описательную норму, содержащую основные отличительные черты.

В качестве основных обеспечительных конструкций, претендующих на звание непоименованных способов обеспечения обязательств можно считать фидуциарный залог и сделки РЕПО, обеспечительную уступку права требования и факторинг, обеспечительное отступное, государственную и муниципальную гарантию, возвратный задаток и задаток в обеспечение предварительного договора, товарную неустойку, способы обеспечения обязательств с использованием векселя, аккредитива, денежного удержания, депонирования денежных средств, составные гражданско-правовые конструкции[10].

Однако, как показывает практика, это далеко не все способы обеспечения обязательств, непоименованные в законе.

Рассмотрим несколько способов обеспечения исполнения обязательств, которые стороны могут предусмотреть в договоре как непоименованные (ст.329 ГК РФ).

\section{1. Товарная неустойка (п. 7 Постановления Пленума ВАС № 81 от 22.12.2011).}

В обороте иногда встречаются условия или отдельные соглашения о товарной неустойке. Такое соглашение вступает в явное противоречие с нормой п. 1 ст. 330 ГК РФ о том, что предметом неустойки являются деньги. Эта норма, очевидно, квалифицирующая. Исходя из этого, нам следует выбрать между тем, чтобы признавать товарную неустойку непоименованным средством обеспечения, и тем, чтобы признавать ее все-таки разновидностью неустойки, расширительно истолковав норму п. 1 ст. 330 ГК РФ о предмете неустойки. Оба варианта вполне приемлемы. Но все же, в силу принципиальной применимости mutatis mutandis (с необходимыми изменениями, поправками, касающимися деталей) всех норм о неустойке к неустойке товарной, видимо, логичнее дать норме о денежном характере неустойки расширительное толкование и признать товарную неустойку, как это делается в большинстве зарубежных стран, разновидностью неустойки[9]. Это сняло бы необходимость обоснования применения ст. 333 ГК РФ и ряда других норм о неустойке (например, о зачетном соотношении с убытками) по аналогии закона[25]. Несмотря на условный характер указанной обеспечительной конструкции, следует признать, что использование товарной неустойки в качестве нестандартного способа воздействия на должника также не исключено. Регулятивный режим института неустойки не настолько сильный, чтобы различие между двумя в целом комплементарными к договорной свободе вариантами стало значительным. Перенос нескольких норм из режима поименованного института неустойки по аналогии закона не представляет какой-то непосильной для судов задачи.

Пункт 7 постановления № 81 фактически «реабилитировал» так называемую вещную или товарную неустойку, которую суды раньше зачастую рассматривали как незаконный способ обеспечения обязательств. При этом Пленум Высшего арбитражного суда указал, что, когда предметом вещной неустойки являются вещи, определенные родовыми признаками, суд может уменьшить их количество применительно к ст. 333 Гражданского кодекса. Кроме того, на основании вышеуказанной статьи суд может уменьшить также сумму задатка, когда она выполняет штрафную функцию. То есть, если задаток остается у получившей его стороны, то сторона, давшая задаток, может требовать уменьшения его суммы и возврата излишне уплаченного. Если же сторона, получившая задаток, должна вернуть его в двойном размере, то она может потребовать уменьшения по правилам ст. 333 Гражданского кодекса половины суммы задатка (той его части, которая выполняет роль штрафа).

Как отмечает, Фёдорова Ю.С. несомненны преимущества товарной неустойки в обстоятельстве, когда у стороны, нарушившей обязательства, нет денежных средств, но есть продукция, которую контрагент применяет в своей деятельности[21]. В этом случае взимание товарной неустойки предупредит длительный судебный процесс, что будет выгодно сторонам договорного обязательства.

\section{2. Страхование жизни и здоровья.}

В имеющейся правоприменительной практике страхованию жизни и здоровья придается значение, как способа, который обеспечивает исполнение всех обязательств. Как правило, это широко применяется в банковской практике при заключении договоров по кредиту. 
В договорах кредита, договор личного страхования представляет собой обязательство (ст. 934 ГК РФ), по которому страховщик обязуется выплатить выгодоприобретателю - кредитору заемщика - страховую сумму при наступлении смерти или гибели, а также в случае причинения вреда здоровью должника[22]. Договор личного страхования является зависимым обязательством: следует судьбе основного обязательства (прекращение, недействительность и т.д.). Согласно п. 3 ст. 167 ГК РФ, по недействительному договору личного страхования страхователь может получить часть страховой премии, пропорциональную оставшемуся периоду действия договора. Но с правовой позиции выгоднее, если страховая услуга оказывается и после прекращения главного обязательства: застрахованы имущественные интересы должника, страховщик приобретает прибыль. Поэтому договор личного страхования должен представлять собой исключение из п. 3 ст. 329 ГК РФ, ввиду того, что необходимо внести в гл. 48 ГК РФ изменения, которые указывали бы, на то что договор личного страхования может быть заключен также в целях обеспечения исполнения обязательства страхователя (застрахованного лица) в пользу его кредитора.

\section{3. Досрочный возврат кредита.}

Основаниями для возврата кредита в досрочном порядке, которые предусмотрены законом, можно отнести все те же, предусмотренные правилами главы 23 «Обеспечение исполнения обязательств» ГК РФ. В частности, в ст. 351 ГК РФ присутствуют установленные основания для исполнения обязательств в досрочном порядке, обеспеченного залогом. Следовательно, залогодержатель в виде банка, имеет право потребовать досрочного исполнения обязательства. Рассмотрим обязательства по уплате процентов и возврату кредита в случаях:

1) если выбыл предмет залога из владения залогодателя, у которого он находился и не соответствовал условиям договора о залоге;

2) если были нарушены правила залогодателем, о замене предмета залога, или потери залога по не зависящим от залогодержателя обстоятельствам.

3) если залогодатель не воспользовался правом, которое предусмотрено п. 2 ст. 345 ГК РФ». При этом пп. 1 и 2 можно будет рассмотреть как частный случай существенного нарушения условий договора, а пп. 3 можно будет отнести к частному случаю существенного изменения обстоятельств.

В случае несоблюдения требований, суд может отказать лицу в защите принадлежащего ему права[23].
Российское гражданское законодательство не содержит специальные правила правового регулирования исполнения реституционного обязательства, а также его динамики (изменение и прекращение). Оно не содержит обязательные предписания для участников делового оборота в отношении того, как должно исполняться реституционное обязательство, может ли оно быть новировано или прекращено отступным, вправе ли стороны прекратить его зачетом, использовать способы обеспечения исполнения обязательства, предусмотренные главой 23 ГК РФ, а также требовать применения мер ответственности за неисполнение реституционного обязательства.

\section{4. Обеспечительный платеж.}

Обеспечительный платеж - это один из способов обеспечения исполнения обязательств. Может применяться любой стороной сделки в качестве контроля над согласованными ранее условиями. Обеспечительный платеж имеет множество названий: обеспечительный взнос, гарантийный платеж, страховой депозит. В судебной практике все наименования обеспечительного платежа имеют равнозначный характер. По условиям взноса (удержания) различают несколько видов обеспечительных платежей:

- выплачиваемый при возникновении неустойки - из обеспечительного платежа удерживается сумма, которая необходима для покрытия неустойки;

- $\quad$ засчитываемый в счет кредита или арендной платы - обеспечительный платеж в полном объеме перечисляется на покрытие части кредита или арендной платы, как правило, является последним (закрывающим) платежом;

- $\quad$ возвращаемый после прекращения срока действия договора - самый распространенный вид обеспечительного платежа, который носит характер ярко выраженной залоговой суммы.

Также, наряду с вышеперечисленными непоименованными в гл. 23 ГК РФ средствами воздействия на должника в системе способов обеспечения исполнения обязательств, по нашему мнению, также в данный список входят:

- Право на приостановление оказания услуг из-за долга по договору[24];

- Купля-продажа недвижимого имущества под условием, по которому переход права собственности на объект недвижимости может ставиться в зависимость от исполнения должником (заемщиком) своих обязанностей по договору займа, а сумма займа является одновременно покупной ценой по договору купли-продажи объекта недвижимости[26]; 


\section{Право и политика 6 (186) • 2015}

- Лизинг (приобретение лизингодателем права собственности на предмет лизинга)[12];

- Сохранение права собственности за продавцом после передачи владения покупателю (ст.491 ГК РФ);

- Обеспечительная уступка права требования в факторинге (п. 2 ст. 831 ГК РФ);

- Обязательное страхование вкладов (п. 1 ст. 840 ГК РФ).

Однако отметим, что данный список не совсем коррелирует с научной доктриной, законодательством и судебной практикой. Строго говоря, способы обеспечения исполнения обязательств - это механизмы, гарантирующие исполнение основной обязанности должника в натуре, но большая часть указанных в ГК РФ способов - это механизмы компенсации кредитору его финансовых потерь, но не исполнения основной обязанности (передать товар, выполнить работу, оказать услугу). Тем не менее, это не делает такие механизмы невостребованными.

Теоретически методов гарантировать натуральный или финансовый (замещающий) интерес кредитора на случай неисправности должника довольно много. Это позволяет надеяться, что еще не воспринятые законом и судебной практикой способы со временем станут «легализованы».

Таким образом, непоименованный договор является юридической возможностью самостоятельно создать «нестандартную» договорную модель, а такая возможность есть не что иное, как элемент правоспособности субъектов гражданского права. Содержательную конструкцию непоименованного договора невозможно сопоставить с соответствующей законодательной матрицей. Реальным местом непоименованных договоров является не нормативно-правовая база, а живая практика гражданского оборота.

Для заключения непоименованных договоров и их судебной защиты в настоящее время правовой основой является положение п. 2 ст. 421 ГК РФ, согласно которому стороны могут заключить договор как предусмотренный, так и не предусмотренный законом и иными правовыми актами.

При регулировании обеспечительных средств, непоименованный способ обеспечения не упоминается в части законодательства. Непоименованные способы обеспечения исполнения обязательств делятся на указанные и неуказанные в законе. Каждый способ, показанный в законе, изначально сложился в качестве самостоятельного гражданско-правового института. Другие были выработаны в качестве обеспечительного средства договорной практикой или признаны самостоятельным способом воздействия на должника в судебных решениях.

Полагаем, что в настоящий момент в гражданском законодательстве отсутствует четко сформулированный механизм правового регулирования всех непоименованных средств обеспечения обязательств. Суды, учитывая их истинное назначение, не имеют возможности в полной мере устранить коллизии и пробелы в области применения способов воздействия на должника. На наш взгляд, вопрос о наделении обеспечительным статусом непоименованных договорных конструкций должен быть заранее решен на законодательном уровне, а не определяться в процессе правоприменения.

\section{Библиография:}

1. Брагинский М.И. Основы учения о непоименованных (безымянных) и смешанных договорах. М.: Статут, 2007.

2. Ойгензихт В.А. Нетипичные договорные отношения в гражданском праве. Душанбе, 1984. С. 4 - 19.

3. Антимонов Б.С., Граве К.А. Договор трудового поручения // Ученые записки ВИЮН 1955. Вып. 3. С. 17.

4. Победоносцев К.П. Курс гражданского права. Часть третья: Договоры и обязательства. М.: Статут, 2003.С. 60-61.

5. Гражданское уложение: проект / Под ред. И. М. Тютрюмова. Т.ІІ. СПб., 1910. С. 177.

6. Новицкая Т. Е. Гражданский кодекс РСФСР 1922 года. М.: Зерцало-М, 2002. С. 91.

7. Танага А.Н. Свобода выбора вида заключаемого договора // ЮРИТ-Вестник. № 7, 2002. С. 101-110

8. Грачева И.В., Самсонова А.Е. Государственная гарантия: соотношение частноправовых и публично-правовых начал. Определение Приморского краевого суда от 27.01.2014 по делу № 33-1;

9. Постановления Пленума ВАС РФ от 14.03.2014 № 17

10. Архипов А., Кучеров А. Новые способы обеспечения // ЭЖ-Юрист. № 22. 2003. С. 3

11. Гонгало Б.М. Обеспечение исполнения обязательств. М., 1999. С. 145-151

12. Скворцов В.В. Возможности повышения обеспечительной функции залога за счет изменения норм законодательства о залоге // Гражданин и право. 2002. № 1.

13. Мирнова П.В. О принципе независимости обязательства гаранта в банковской гарантии // Банковское право. 2003. № 1.

14. Сойко Р.П. Особенности правового регулирования банковской гарантии // Банковское право. 2002. № 4.

15. Комиссарова Е. Г., Торкин Д. А. Непоименованные способы обеспечения обязательств в гражданском праве. - М., 2008. - C.101

16. Х Хохлов В. А. Ответственность за нарушение договора по гражданскому праву. - Тольяти, 1997. - С.245 
DOI: $10.7256 / 1811-9018.2015 .6 .15449$

При цитировании этой статьи сноска на доі обязательна

Юридический практикум

\section{References (transliterated):}

1. Braginskii M.I. Osnovy ucheniya o nepoimenovannykh (bezymyannykh) i smeshannykh dogovorakh. M.: Statut, 2007.

2. Oigenzikht V.A. Netipichnye dogovornye otnosheniya v grazhdanskom prave. Dushanbe, 1984. S. 4 - 19.

3. Antimonov B.S., Grave K.A. Dogovor trudovogo porucheniya // Uchenye zapiski VIYuN 1955. Vyp. 3. S. 17.

4. Pobedonostsev K.P. Kurs grazhdanskogo prava. Chast' tret'ya: Dogovory i obyazatel'stva. M.: Statut, 2003.S. 60-61.

5. $\quad$ Novitskaya T. E. Grazhdanskii kodeks RSFSR 1922 goda. M.: Zertsalo-M, 2002. S. 91.

6. Tanaga A.N. Svoboda vybora vida zaklyuchaemogo dogovora // YuRIT-Vestnik. № 7, 2002. S. 101-110

7. Gracheva I.V., Samsonova A.E. Gosudarstvennaya garantiya: sootnoshenie chastnopravovykh i publichno-pravovykh nachal. Opredelenie Primorskogo kraevogo suda ot 27.01.2014 po delu № 33-1;

8. Arkhipov A., Kucherov A. Novye sposoby obespecheniya // EZh-Yurist. № 22. 2003. S. 3

9. Gongalo B.M. Obespechenie ispolneniya obyazatel'stv. M., 1999. S. 145-151

10. Skvortsov V.V. Vozmozhnosti povysheniya obespechitel'noi funktsii zaloga za schet izmeneniya norm zakonodatel'stva o zaloge // Grazhdanin i pravo. 2002. № 1.

11. Mirnova P.V. O printsipe nezavisimosti obyazatel'stva garanta v bankovskoi garantii // Bankovskoe pravo. 2003 . № 1.

12. Soiko R.P. Osobennosti pravovogo regulirovaniya bankovskoi garantii // Bankovskoe pravo. 2002. № 4.

13. Komissarova E. G., Torkin D. A. Nepoimenovannye sposoby obespecheniya obyazatel'stv v grazhdanskom prave. - M., 2008. - S.101

14. Khokhlov V. A. Otvetstvennost' za narushenie dogovora po grazhdanskomu pravu. - Tol'yati, 1997. - S.245 